\title{
Environmental assessment and improvement strategies for electric bus operations
}

\author{
Lay Eng Teoh ${ }^{1 *}$, Siew Yoke Goh ${ }^{1}$, and Hooi Ling Khoo ${ }^{1}$ \\ ${ }^{1}$ Lee Kong Chian Faculty of Engineering and Science, Universiti Tunku Abdul Rahman, 43000, \\ Kajang, Selangor, Malaysia
}

\begin{abstract}
In accordance with worldwide environmental problems and fossil oil dependency concern, green mobility with electric buses is receiving increasing attention as an essential road transport. Environmentally, electric buses emerge as a promising solution in particular to alleviate the emission and noise pollution. Nevertheless, there is no available method on how to quantify green (environmental) performance of electric buses that could provide proper guidance to the bus operators. Therefore, this study aims to construct a green index assessment and improvement framework for electric buses by capturing bus noise, emission and energy consumption level explicitly. The proposed framework, which is capable of quantifying the green level of electric bus operations, plays a vital role in improving the green performance of bus operating system, by considering numerous operational aspects. In order to examine the applicability of the proposed approach, an illustrative case study, focusing on the electric bus operations of Putrajaya (Malaysia), is analyzed accordingly. The resultant findings show that the green performance of electric buses would be different at varying degrees, depending on various inter-correlated factors. It is anticipated that this study may reveal some beneficial insights for the bus operators to operate environmental-friendly electric buses feasibly.
\end{abstract}

\section{Introduction}

Globally, it was found that the emission from road transportation has resulted in an acute threat to air quality and global warming, in view of the fact that transportation activities generate numerous side effects, including air and noise pollution that certainly necessitates attentive concern from the stakeholders (e.g. policy makers, operators, public, etc.). From the transportation sector, the main contributors to greenhouses gas (GHG) emissions are carbon dioxide $\left(\mathrm{CO}_{2}\right)$, methane $\left(\mathrm{CH}_{4}\right)$ and nitrous oxide $\left(\mathrm{N}_{2} \mathrm{O}\right)$ [1, 2]. As the transportation sector accounted for more than $25 \%$ of worldwide energy consumption, the resultant side effects must be tackled wisely [3]. In addition, fossil oil dependency concern and increasing demand for urban transport (including public bus) thus highlights the need for green transport [4].

Correspondingly, the deployment of electric bus (EB), as a viable public transport, has emerged as a promising alternative to stimulate green mobility $[3,5]$. Electric bus is an emerging technology which is environmentally-friendly and it is specially designed to reduce

*Corresponding author: teohle@utar.edu.my 
carbon emission $[6,7]$. In addition to the benefits on social economy, a proper-designed operating system of EB would encourage the mode shift from the private vehicle to public transport. From year to year, battery capacity and charging technology of EB have been improving gradually. However, there are some operational concerns (i.e. battery limitation, high cost and long charging time) in applying EB in practice [8, 9]. To tackle these limitations, a well-planned EB operating system is certainly required, in particular to enhance its environmental (green) performance which would contribute beneficially not only to the bus operators but also to the environment as well as the society.

Thus, this paper aims to develop an environmental assessment and improvement framework for EB operations, by capturing explicitly three vital elements, namely the energy consumption, emission and noise of EB. The developed approach is capable of quantifying the green performance of EB operations by considering a variety of operating characteristics. It is also playing a vital role to improve the overall green performance of EB operating system by suggesting numerous beneficial improvement strategies. In addition, it is useful to assess the effectiveness of the improvement strategies. Concisely, it is anticipated that the developed approach and also the resultant findings would assist the operator of EB in providing better and greener EB services.

\section{Literature review}

The operation of EB is supported by numerous degrees of electrification that depend on the configuration of the propulsion system $[10,11]$. There are several types of EB, including hybrid electric, fuel cell electric and battery electric buses $[12,13]$. In order to support the operation of EB, there are numerous types of battery in the market, for instances lead acid, NiMH (nickel-metal hydride battery) and lithium-ion batteries [14]. Comparatively, lithiumion batteries perform better than lead acid and NiMH batteries in terms of power, battery lifetime and energy density. Fontaínhas et al. [15] highlighted that EB has several benefits, incuding silent operation, zero tailpipe emissions and high tank-to-wheel efficiency, in comparison to internal combustion engine vehicles. However, there are some challenges in using EB. The three major concerns are the limitation of battery capacity, scarcity of charging facilities and long charging duration $[3,16,17]$. Therefore, a proper operational assessment and planning is indeed required to operate green EB viably.

There are numerous studies that analyze the operations of EB. As addressed below, these studies could be grouped according to the discussions that focus on the environmental aspect and other areas (economic, route design and charging infrastructure).

\subsection{Environmental aspect}

According to the existing literature, the environmental analysis of EB could be categorized by three aspects (influential factors), namely energy consumption, emission and noise.

Electric buses operate with varying energy sources, for instance the electricity for battery $\mathrm{EB}$, hydrogen for fuel cell EB and fossil or biofuel for hybrid EB [18]. The respective energy source demonstrates specific characteristics that affect the bus performance. Energy efficiency, as the net volume of energy required for one kilometer travel, is greatly influenced by energy storage systems $[19,20]$. Thus, evaluating the energy consumption is crucial in planning and managing EB operations. Specifically, load factor, topography, outdoor temperature, number of bus stops, and driving behavior have been found to greatly affect the energy consumption for EB [21]. In particular, Gallet et al. [22], Perrotta et al. [23] and Bunzel and Baker [24] determined the usage of energy in supporting the operating system of EB. The findings of Gallet et al. [22] showed that the driving conditions (especially for different bus routes and operating time) would greatly affect the overall energy consumption. 
In addition, Perrotta et al. [23] found that the most demanding bus route required more energy to complete the bus operations while Bunzel and Baker [24] revealed that the energy requirement of a specific $\mathrm{EB}$ is relatively influenced by a speed-time profile and also environmental parameters (for instance, ambient temperature). In short, these studies highlighted that it is crucial to consider the characteristics of the respective bus route into analysis. However, some influential factors (e.g. load factor and bus type) are not considered explicitly in the energy determination.

To quantify the generated GHG emission of EB, the assessment of Well-to-Wheel (WTW) comprises two stages, namely Well-to-Tank (WTT) and Tank-to-Wheel (TTW). Specifically, WTT measures the GHG emission at both production and distribution stages while TTW measures the GHG emissions during the usage stage. Typically, TTW assessment is conducted according to the operational data or vehicle simulation models. In overall, the WTW assessment signifies that battery EB has great potential to reduce GHG emissions. Besides, it was found that EB could control the rapid growth of GHG emission, by adopting the best charging efficiency and electricity distribution loss [4]. In addition, He et al. [25] and Dreier et al. [26] revealed that there is a closed linkage between the energy consumption and WTW. In particular, the energy consumption would proportionally affect WTW emissions of $\mathrm{CO}_{2}$ and air pollutants [25] while TTW energy consumption, that could influence GHG emissions, can vary up to $77 \%$ for different operation routes, operating times and bus types [26].

Additionally, it was found that EB produces a lower level of noise and vibration due to the absence of mechanical parts. The noise level of EB comprises exterior, interior and indoor noise. In comparison, EB emits a lesser level of noise than diesel buses, i.e. up to 8dBA difference (for exterior cruising stage), especially with a bus speed below $50 \mathrm{~km} / \mathrm{h}$ [27]. Specifically, noise pollution is recognized as a major health problem in many cities, and it was found to be far harder to solve than air pollution. Besides, it was reported that bus noise could generate several consequences including annoyance, sleep disruption, increased incidence of arterial hypertension, myocardial infarction, and stroke [28]. Ross and Staiano [29] and Boren [30] compared the noise level generated by diesel and EB. It was found that the noise level of EB would be affected by bus speed for which engine noise will dominate for diesel buses when speeds are low [29]. And, Boren [30] showed that significant savings in using EB is primarily contributed not only by decreased noise level, but also zero emissions during the operation, as well as the reduction of energy consumption.

\subsection{Other relevant studies}

Generally, the economic studies of EB primarily emphasized on the cost-benefit analysis of operating EB. For the operational performance of EB, most studies discussed the route design and charging infrastructure. However, most of these analyses were discussed separately.

In terms of the economic performance of EB, total cost of ownership (TCO) of EB has been identified as one of the major challenges of using EB. It includes the manufactured price of a bus and also the cost for maintenance, operation, energy distribution, infrastructure, emission, insurance and end-of-life [31]. For manufacturing cost, EB is found to be more expensive than their diesel buses. Yet, it performs better than the diesel bus with an average reduction of $80 \%$ in operational cost. In terms of the infrastructure cost, the opportunity battery EB is considered as the most expensive option. Comparatively, overnight charging requires major infrastructure modification for charging stations while the opportunity charging requires more charging points [19]. Despite the various efforts to estimate the TCO of $\mathrm{EB}$, the literatures highlighted that there is a plenty of uncertainty in the analysis [32]. 
With regard to the route design of $\mathrm{EB}$, traditional vehicle routing problem (VRP) mainly concerns on the economic impact of vehicle routes. Inevitably, the inclusion of more objectives and practical constraints consequently leading to new routing models, application scenarios and also more complicated optimization problems [33]. Correspondingly, Genetic Algorithm emerges as a promising metaheuristic approach to solve EB route design problem due to its capability of providing a robust near optimal solution in a reasonable time [34-36]. Besides, Zhu and Chen [37] and Mohamed et al. [38] showed that the operation and route design of EB could be influenced by the charging facility. It was also found that increasing investment of the bus fleet will result in a higher level of charging demand which subsequently generates additional burden on the charging facility [37]. Comparatively, although flash and opportunity charging are more feasible than overnight charging, they suffer from high and intermittent power demand [38]. In addition, Fusco et al. [39] showed that the high investment and personnel costs of EB could be compensated by lower energy and environmental costs. However, they merely compared different technology alternatives instead of finding the best solution for transit design.

Pertaining to the charging infrastructure of EB, Rogger et al. [40] and Qin et al. [41] showed that there are some operational constraints for which battery weight was found to be a limiting factor for the installable battery capacity in an EB [40]. Besides, a higher charging threshold would result in more charging events and shorter charging duration [41]. By optimizing the distribution of charging infrastructure for EB, Xylia et al. [42] showed that the shorter distances between bus stops favor the use of EB and the optimal location to locate charging facilities would concentrate at major hubs of public bus. In particular, these studies highlighted several vital elements (including battery weight/size, charging period and locations) that should be taken into consideration in planning EB operations.

Concisely, the afore-mentioned studies highlighted that there are numerous elements that ought to be captured explicitly in assuring a viable EB operating system. Yet, apparently there is limited study that examines the overall green performance of EB operating network. Thus, it is of utmost important to have a proper-developed approach on how to quantify the green performance of EB in order to operate a better and greener EB operating system.

\section{Methodology}

\subsection{List of notations}

The following presents the list of notations used for the developed framework.

$\begin{array}{cl}C & \text { Resistance coefficient of bus } \\ C a t^{n} & \text { Cumulative percentage of operating routes in the category } n \\ D_{r} & \text { Length of bus route } r \\ e_{i} & \text { GHG emission factor of electricity mixes } i \\ f & \text { Friction force of bus } \\ g & \text { Acceleration of gravity } \\ F_{E B} & \text { Bus frequency } \\ i & \text { Type of electricity mixes } \\ j & \text { Type of green index } \\ l & \text { Electricity loss of power transmission system } \\ L F & \text { Load factor of bus } \\ m & \text { Total mass of bus }\end{array}$




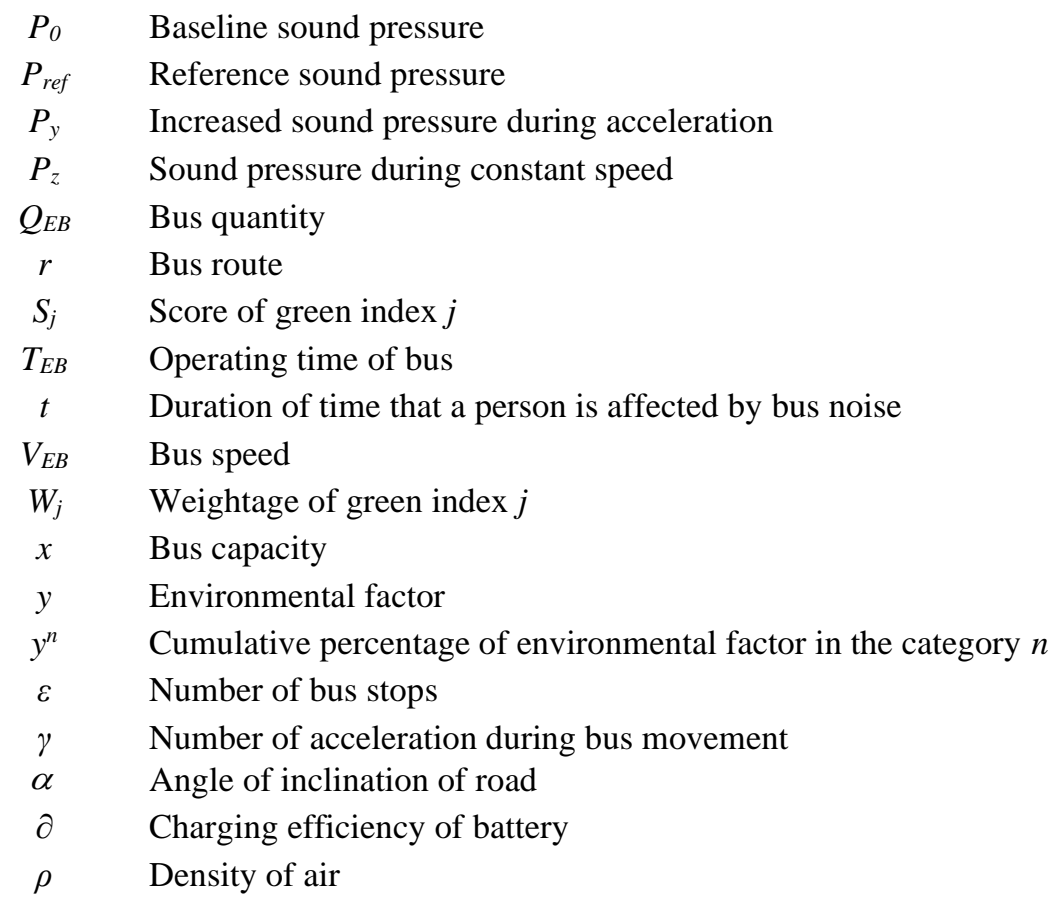

\subsection{Assessment framework}

In accordance to the environmental concern, this paper aims to quantify the green performance of EB operations so that the enhancement on the operational strategies of EB could be conducted in order to assure a greener operating system. As displayed in Fig.1, the proposed methodology involves numerous environmental factors that constitute the overall green level of EB operations in terms of Green Performance Index (GPI).

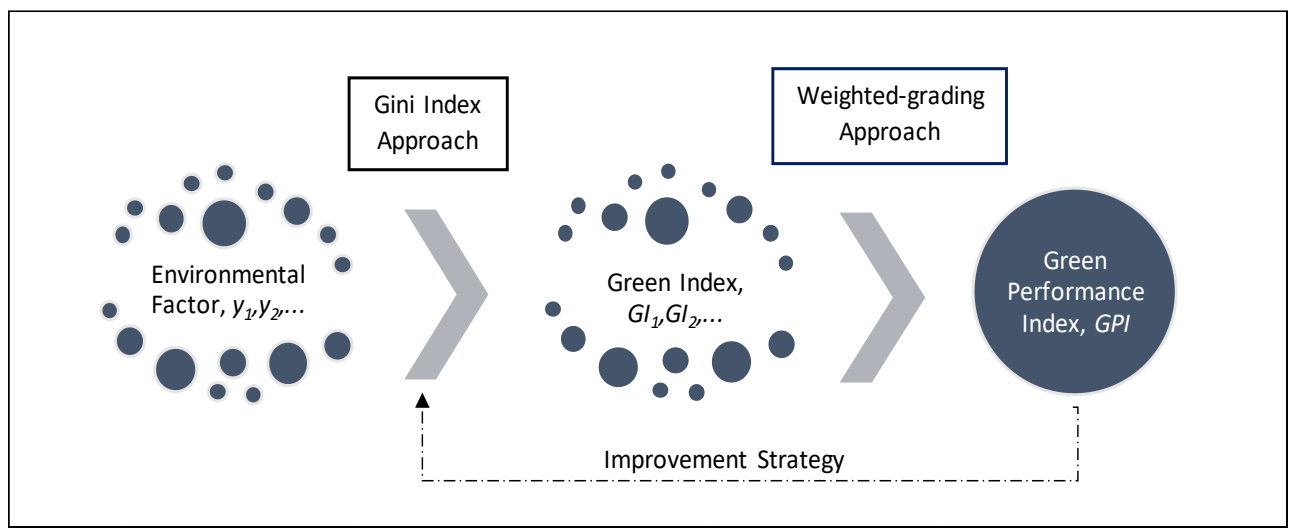

Fig. 1. The assessment framework of Green Performance Index (GPI).

As displayed in Fig. 1, it could be seen that various environmental factors, $y$ (e.g. energy consumption, emission and noise) can be captured specifically in order to obtain the respective Green Index (GI). This can be done with the aid of Gini Index Approach (GIA). In other words, the proposed assessment framework is able to quantify three major green indexes, namely Green Energy Index (GEI), Green Emission Index (GMI) and Green Noise 
Index (GNI). Subsequently, a Weighted-grading Approach (WGA) is applied to integrate the obtained green indexes in order to quantify the GPI as a green indicator. In addition, different improvement strategy could be adopted to yield a better GPI. The element of GPI is playing a crucial role not only to reveal the green performance of the EB at present by considering numerous influential factors (including energy consumption, emission and noise), but also to provide constructive recommendations on the beneficial improvement strategies that can be carried out by the bus operators in order to enhance the environmental performance of the entire operating network of EB. Furthermore, the effectiveness of the respective strategy could be determined for the further action of the bus operators in order to provide EB service environmentally.

The idea of GIA was borrowed from the concept of Gini coefficient (index) in measuring the degree of equality with the scale that ranges from zero to one. When a data set (i.e. the operational records of $\mathrm{EB}$ ) is closer to each other (with a higher equality), it would tend to produce a smaller variance which in fact reflect a better green performance. Thus, if EB operators could reduce the amount of energy consumption, emission and noise effectively, the resultant EB operating network would generate less pollutants and hence a smaller value of variance could be obtained (with a smaller value of average too). On the other hand, for a data set with a wider gap (with a lower level of equality), it possesses the tendency to have a higher value of Gini coefficient which, in fact, indicates a poorer green performance. In other words, a greener performance with a lesser amount of energy consumption, emission and noise would result in a lower Gini index, average and variance. Thus, Gini index is adopted to quantify the green index of EB. In practice, a greener performance could be achieved if EB operators could carry out some improvement strategies effectively [43].

Correspondingly, the Green Index (GI) of the respective environmental factor could be determined as follow:

$$
G I=1-\sum_{\forall n}\left(y^{n}+y^{n-1}\right)\left(C a t^{n}-C a t^{n-1}\right)
$$

In overall, $G I \rightarrow 0$ indicates that the green level of the EB is getting better by producing less energy consumption, emission and noise for the bus operation. On the other hand, $G I \rightarrow 1$ signifies a poorer performance of green level where more energy consumption, emission and noise are produced during the bus operation.

\subsubsection{Green Energy Index (GEI)}

For a particular operating bus route $r$, the daily energy consumption level of EB, $E_{r}$ can be expressed as follows:

$$
E_{r}=\sum_{\forall r} L F\left(\left((f \cos (\alpha)+\sin (\alpha)) m g+\frac{1}{2} C A \rho\left(V_{E B}\right)^{2}\right) V_{E B} T_{E B}\right) F_{E B} Q_{E B}
$$

Equation (2) is a modified version of total energy consumption from Bunzel and Baker [24] by adding the element of load factor $(L F)$, bus operating time $\left(T_{E B}\right)$, bus frequency $\left(F_{E B}\right)$ and bus quantity $\left(Q_{E B}\right)$ in order to capture the EB daily operations realistically. Consequently, the Green Energy Index (GEI) can be computed as follows:

$$
G E I=1-\sum_{\forall n}\left(E_{r}^{n}+E_{r}^{n-1}\right)\left(C a t^{n}-C^{n} t^{n-1}\right)
$$

for which $E_{r}^{n}$ and $C a t^{n}$ respectively refers to the cumulative percentage of energy consumption and EB operating routes in the category $n$. Specifically, $G E I \rightarrow 0$ indicates that the green level of energy consumption is better by consuming less energy for the bus operations. Conversely, $G E I \rightarrow 1$ shows that the EB consumes more energy for operations for which the green performance of $\mathrm{EB}$ in terms of energy performance is poorer. 


\subsubsection{Green Emission Index (GMI)}

Well-to-Wheel (WTW) analysis, which is generally applied in assessing the GHG emission of bus, consists of two stages which is Well-to-Tank (WTT) and Tank-to-Wheel (TTW) [26]. For the stage of WTT, the GHG emission is produced during the fuel production and supply while at the stage of TTW, the GHG emission is produced when energy is used during the bus operation to support the bus movement. Comparing with conventional bus, EB has zero emission from its tailpipe, but it has indirect waste gas emission (at the stage of WTT) during electricity generation. And, there are various waste gas emissions that could be incurred during the electricity generation process. As presented below, Equation (4) is modified from Song, et al. [4] by adding the element of load factor $(L F)$, bus frequency $\left(F_{E B}\right)$ and bus quantity $\left(Q_{E B}\right)$ in order to quantify the daily emission level of $E B, E M_{r}$.

$$
E M_{r}=\sum_{\forall r} L F\left(\sum_{\forall i} \frac{E_{r} e_{i}}{\partial \times(1-l)_{i}}\right) F_{E B} Q_{E B}
$$

And, the Green Emission Index (GMI) can be computed as follows:

$$
G M I=1-\sum_{\forall n}\left(E M_{r}^{n}+E M_{r}^{n-1}\right)\left(C^{n} t^{n}-C_{a t}^{n-1}\right)
$$

for which $E M_{r}^{n}$ and $C a t^{n}$ respectively refers to the cumulative percentage of emission level and EB operating routes in the category $n$. GMI $\rightarrow 0$ indicates that the green level of EB in terms of emission is better by producing less pollutant during the bus operation while $G M I \rightarrow 1$ signifies that the green performance of EB is poorer with more emission.

\subsubsection{Green Noise Index (GNI)}

The total noise level of EB considers explicitly two types of noise, namely exterior and interior noise. Exterior noise is produced when the bus accelerates, i.e. when the bus is taking off, speeding, passing through traffic light or bus stop. Meanwhile, interior noise is produced when the bus operates on constant speed or idling. As shown in Equation (6), the total noise of EB is formed by both exterior and interior noise. Besides, the element of load factor $(L F)$, bus frequency $\left(F_{E B}\right)$ and bus quantity $\left(Q_{E B}\right)$ are considered in quantifying the total noise level of EB operations. By modifying the total noise formula of Boren [30], the daily noise level of EB, $L_{r}$ can be expressed as follows.

$$
L_{r}=\sum_{\forall r} L F\left(10 \log \left[\frac{V_{E B}}{D_{r}} \int_{0}^{\frac{D_{r}}{V_{E B}}} \frac{P_{0}^{2}\left(\frac{D_{r}}{V_{E B}}\right)+\left(P_{y}+P_{0}\right)^{2}(\varepsilon+\gamma) t}{P_{r e f}^{2}} d t\right]+10 \log \left[\frac{V_{E B}}{D_{r}} \int_{0}^{\frac{D_{r}}{V_{E B}}} \frac{P_{z}^{2}}{P_{r e f}^{2}} d t\right]\right) F_{E B} Q_{E B}
$$

Correspondingly, the Green Noise Index (GNI) can be computed as below.

$$
G N I=1-\sum_{\forall n}\left(L_{r}^{n}+L_{r}^{n-1}\right)\left(\text { Cat }^{n}-C^{n} t^{n-1}\right)
$$

for which $L_{r}^{n}$ and $C a t^{n}$ respectively refers to the cumulative percentage of noise level and operating routes of EB in the category $n . G N I \rightarrow 0$ indicates that the green level of bus noise is better by producing lesser noise during the bus operations. On the contrary, $G N I \rightarrow 1$ shows that the green performance of EB in terms of noise level is poorer (by producing more noise). 


\subsubsection{Green Performance Index (GPI)}

In order to quantify the green performance of EB operations, the developed green indicator, namely the GPI captures three green indexes, namely GEI, GMI and GNI (as addressed above). In overall, the element of GPI could be determined straight-forwardly as follows:

$$
G P I=\sum_{\forall j} W_{j} S_{j}
$$

for which $W_{j}$ and $S_{j}$ reflects the weightage and score for the respective green index, $j$. And, $\sum_{\forall j} W_{j}=1$. In order to determine the GPI, a designated Weighted-grading Approach (WGA) is proposed as shown in Table 1. WGA has altogether eight grades from grade I to VIII. The resultant grade plays a significant role in reflecting the achievement of the green performance for which grade I (with a score of 4.00) represents the best (greenest) environmental performance while grade VIII (with a score of 0.00) shows the worst green performance. In order to finalize the grade, the green index for each environmental factor (i.e. energy consumption, emission and noise) would be categorized accordingly and subsequently Equation (8) is applied to evaluate the GPI by selecting a particular set of weightage. Various sets of weightage can be considered according to the preference and priority of the bus operator towards the respective environmental factor. In other words, the weightage can be adjusted flexibly subject to the needs of the bus operators.

Table 1. Weighted-grading approach for Green Performance Index (GPI).

\begin{tabular}{|c|c|c|}
\hline Green Index (GI) & Score, $\boldsymbol{S}$ & Grade \\
\hline $0.00-0.20$ & 4.00 & I \\
\hline $0.21-0.25$ & 3.67 & II \\
\hline $0.26-0.30$ & 3.33 & III \\
\hline $0.31-0.35$ & 3.00 & IV \\
\hline $0.36-0.40$ & 2.67 & V \\
\hline $0.41-0.45$ & 2.33 & VI \\
\hline $0.46-0.50$ & 2.00 & VII \\
\hline $0.51-1.00$ & 0.00 & VIII \\
\hline
\end{tabular}

\section{An illustrative case study}

Putrajaya, Malaysia has been targeted as a Green City in accordance to the efforts by the government of Malaysia in reducing the emission of $\mathrm{CO}_{2}$ by $60 \%$ [44]. Therefore, Putrajaya was chosen as the study area. Nadi Putra, a bus company, was founded in the year 1999 and it is one of the subsidiaries of Putrajaya Corporation. Nadi Putra operates two types of public bus, namely a 12-meter long type that can ferry up to 63 passengers and a 7-meter long minibus that can ferry up to 40 passengers. The study area of Putrajaya is displayed in Fig. 2 . There are altogether 10 bus routes in operations and the EB are equipped with a $300 \mathrm{kWh}$ capacity titanium-ion battery. To support the operations of EB, there are three terminals which function as the departure point for all buses and these terminals also serve as the final stop for daily operations. They are also designed to function as charging stations. For analysis purposes, it is assumed that all buses use the same type of charging facility, namely slow charging that requires eight hours to get fully charged. 


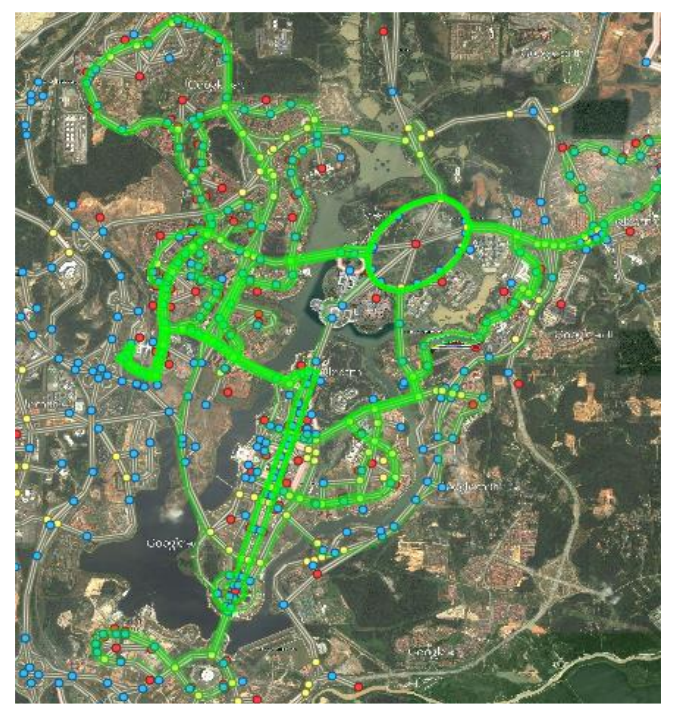

Fig. 2. The study area of Putrajaya, Malaysia.

In order to test the applicability of the proposed framework in assessing and improving the green performance of EB operations, the relevant data inputs as compiled accordingly [4, 22, 30, 45-47] are shown as below.

- Bus capacity, $x=63$

- Angle of inclination of road, $\alpha=3^{0}$

- Acceleration of gravity, $g=9.8 \mathrm{~m} / \mathrm{s}^{2}$

- Resistance coefficient of bus, $C=0.4666$

- Friction force of bus, $f=0.008$

- Density of air, $\rho=1.1839 \mathrm{~kg} / \mathrm{m}^{3}$

- Electricity loss of power transmission system, $l=3.17 \%$

- Charging efficiency of battery, $\partial=94 \%$

- $\mathrm{GHG}$ emission factor, $e_{1}=0.76 \mathrm{~kg} \mathrm{CO}_{2} \mathrm{eq} / \mathrm{kWh}$

- $\mathrm{GHG}$ emission factor, $e_{2}=0.71 \mathrm{~kg} \mathrm{CO} \mathrm{CO}_{2} \mathrm{eq} / \mathrm{kWh}$

- $\mathrm{GHG}$ emission factor, $e_{3}=0.78 \mathrm{~kg} \mathrm{CO} 2 \mathrm{eq} / \mathrm{kWh}$

- Reference sound pressure, $P_{\text {ref }}=2 \times 10^{-5} \mathrm{Pascal}$

- Baseline sound pressure, $P_{0}=0.02 \mathrm{Pascal}$

- Sound pressure during constant speed, $P_{z}=0.037$ Pascal

Besides, Tables 2 and 3 present some of the data input used to quantify the energy consumption and noise of bus.

In addition, Table 4 shows the specific sets of weightage selected in quantifying the green performance. For analysis purposes, the weightages of GEI and GMI were outlined to be double than the weightage of GNI for Set A while Set B considers equal weightage for all indices (GEI, GMI and GNI). It is anticipated that weightage selection could impact the green performance of the entire EB operational system. In practice, the value of weightage can be determined by the bus operator according to specific need and preference. In other words, the developed approach is relatively flexible to meet the need and/or preference of the bus operator for which the selection of weightage may vary accross bus operators. 
Table 2. Data input to quantify energy consumption [47, 48].

\begin{tabular}{|l|c|c|c|c|c|c|c|c|c|c|}
\hline \multicolumn{1}{|c|}{ Bus route, $\boldsymbol{r}$} & $\mathbf{R 1}$ & $\mathbf{R 2}$ & $\mathbf{R 3}$ & $\mathbf{R 4}$ & $\mathbf{R 5}$ & $\mathbf{R 6}$ & $\mathbf{R 7}$ & $\mathbf{R 8}$ & $\mathbf{R 9}$ & $\mathbf{R 1 0}$ \\
\hline Bus speed, $V_{E B}(\mathrm{~km} / \mathrm{h})$ & 55 & 55 & 45 & 45 & 45 & 40 & 40 & 40 & 55 & 45 \\
\hline Length of bus route, $D_{r}(\mathrm{~km})$ & 28.59 & 22.86 & 23.2 & 21.87 & 24.6 & 22.86 & 29.13 & 26.57 & 32.7 & 25.88 \\
\hline Operating time of bus, $T_{E B}($ hour $)$ & 0.52 & 0.42 & 0.52 & 0.49 & 0.55 & 0.57 & 0.73 & 0.66 & 0.59 & 0.58 \\
\hline Total mass of bus, $m\left(10^{3} \mathrm{~kg}\right)$ & 13.1 & 13.5 & 15.6 & 15.8 & 15.8 & 16.2 & 16.2 & 16.0 & 13.1 & 14.5 \\
\hline Bus frequency, $F_{E B}$ & 3 & 4 & 4 & 3 & 3 & 3 & 3 & 3 & 3 & 3 \\
\hline Bus quantity, $Q_{E B}$ & 18 & 14 & 14 & 16 & 17 & 16 & 19 & 17 & 19 & 19 \\
\hline Load factor, $L F(\%)$ & 10 & 20 & 70 & 75 & 75 & 85 & 85 & 80 & 10 & 45 \\
\hline
\end{tabular}

Table 3. Data input to quantify bus noise [30, 47].

\begin{tabular}{|l|c|c|c|c|c|c|c|c|c|c|}
\hline Bus route, $\boldsymbol{r}$ & $\mathbf{R} 1$ & $\mathbf{R 2}$ & $\mathbf{R 3}$ & $\mathbf{R 4}$ & $\mathbf{R 5}$ & $\mathbf{R 6}$ & $\mathbf{R 7}$ & $\mathbf{R 8}$ & $\mathbf{R 9}$ & $\mathbf{R 1 0}$ \\
\hline Number of bus stops, $\epsilon$ & 29 & 22 & 23 & 26 & 23 & 26 & 24 & 25 & 38 & 24 \\
\hline $\begin{array}{l}\text { Number of acceleration during bus } \\
\text { movement, } \gamma\end{array}$ & 31 & 25 & 31 & 29 & 33 & 34 & 44 & 40 & 36 & 35 \\
\hline $\begin{array}{l}\text { Increased sound pressure during } \\
\text { acceleration, } P_{y}\left(10^{-4} \text { Pascal) }\right.\end{array}$ & 725 & 725 & 442 & 442 & 442 & 290 & 290 & 290 & 725 & 442 \\
\hline $\begin{array}{l}\text { Duration of time that a person is } \\
\text { affected by bus noise, } t \text { (second) }\end{array}$ & 5 & 5 & 7 & 7 & 7 & 10 & 12 & 10 & 5 & 4 \\
\hline
\end{tabular}


As presented in Table 5, a benchmark scenario (for Nadi Putra bus operations) is analyzed by using the operational data collected in the year 2015 as well as the data inputs as stated earlier. Besides, three improvement strategies were outlined with the aim to improve the GPI. Each improvement strategy emphasizes on different operational aspect so that a better result of GPI can be achieved. Using a different strategy is helpful to reveal the effectiveness of each proposed improvement strategy on the respective environmental factor as well as the overall green performance in terms of the GPI.

As indicated in Table 5, Strategy 1 focuses on load factor increment for the bus routes with a relatively low level of passengers' demand (those below $50 \%$ of load factor). By increasing load factor, it is anticipated that the amount of emitted pollutants per passenger would be lesser and the EB operating network will be greener [49]. To keep a higher demand (load factor), EB bus operators may implement numerous attractive marketing strategy (e.g., by offering a cheaper bus fare including seasonal rebates) and also improving the overall bus service (e.g. punctuality and reliability).

Strategy 2 aims to adjust the bus frequency from two aspects, namely frequency reduction and removal (if necessary). This could be done on the bus routes with a low load factor (e.g. below $50 \%$ ). For the identified bus routes, the bus frequency may be reduced while aiming to increase the load factor (up to 50\%). Besides, some bus routes may be eliminated (frequency removal) if the load factor is too low (e.g. only $10 \%$ of load factor). The restructure of the bus frequency from these aspects is vital to the green environment in view of the fact that fewer bus frequencies may produce less pollutant [50].

Table 4. Two sets of weightage in assessing Green Performance Index.

\begin{tabular}{|c|c|c|c|}
\cline { 2 - 4 } \multicolumn{1}{c|}{} & \multicolumn{3}{|c|}{ Weightage (\%) } \\
\cline { 2 - 4 } \multicolumn{1}{c|}{} & $\begin{array}{c}\text { Green Energy Index } \\
\text { (GEI) }\end{array}$ & $\begin{array}{c}\text { Green Emission Index } \\
\text { (GMI) }\end{array}$ & $\begin{array}{c}\text { Green Noise Index } \\
\text { (GNI) }\end{array}$ \\
\hline Set A & 40 & 40 & 20 \\
\hline Set B & $33 \frac{1}{3}$ & $33 \frac{1}{3}$ & $33 \frac{1}{3}$ \\
\hline
\end{tabular}

Table 5. The outlines for benchmark scenario and improvement strategies.

\begin{tabular}{|c|l|}
\hline Scenario/Strategy & \multicolumn{1}{c|}{ Description } \\
\hline Benchmark scenario & Existing operational data (without improvement strategy) \\
\hline Strategy 1 & Increase load factor up to 50\% for certain bus routes \\
\hline Strategy 2 & Adjust bus frequency and increase load factor for certain bus routes \\
\hline Strategy 3 & Fleet planning and increase load factor for certain bus routes \\
\hline
\end{tabular}

For Strategy 3, fleet planning (in terms of using different bus capacity) is proposed in order to accommodate varying levels of passengers' demand. A smaller size of EB could be used to serve the bus routes with a low load factor (i.e. below 50\%). It is anticipated that the operations with smaller bus would produce less pollutant (mainly due to the reduction of the total mass of bus). In view of the fact that a smaller bus capacity is used for the designated bus routes, the load factor may increase accordingly.

\section{Results discussions}

The resultant findings of green indexes (for GEI, GMI and GNI) are presented in Table 6 while Table 7 displays the results of GPI. Pertaining to the green performance of EB in terms of GEI, Table 6 shows that Strategy 1 yields the highest improvement level (at 56.57\%), followed by Strategy 2 and 3. This shows that load factor increment (Strategy 1) has the most significant impact in improving GEI (in terms of the energy consumption). Among the 10 
operating routes, the load factor of bus routes R1, R2, R9 and R10 has been increased to $50 \%$ which results in an average load factor of $67 \%$ for the entire operating network.

As for GMI, Strategy 1 also attained the most promising (highest) improvement level at $41.84 \%$, followed by Strategy 2 which improved $28.69 \%$. In comparison to Strategy 3, this shows that the increasing load factor (Strategy 1) and adjusting bus frequency (Strategy 2) could reduce the emission level effectively. For Strategy 2, the bus routes R1 and R9 were removed due to a very low load factor (only 10\%) while the frequency of bus routes R2 and R10 were revised to one. This has reduced altogether a total of 11 bus frequencies (by adjusting four bus routes, i.e. R1, R2, R9 and R10).

Table 6. The results of green indexes.

\begin{tabular}{|c|c|c|c|c|c|c|c|}
\hline \multirow[t]{2}{*}{$\begin{array}{l}\text { Scenario/ } \\
\text { Strategy }\end{array}$} & \multicolumn{2}{|c|}{$\begin{array}{c}\text { Green Energy } \\
\text { Index (GEI) }\end{array}$} & \multicolumn{2}{|c|}{$\begin{array}{c}\text { Green Emission } \\
\text { Index (GMI) }\end{array}$} & \multicolumn{2}{|c|}{$\begin{array}{l}\text { Green Noise } \\
\text { Index (GNI) } \\
\end{array}$} & \multirow{2}{*}{$\begin{array}{c}\text { Average } \\
\text { Improvement } \\
\text { Level }\end{array}$} \\
\hline & Index & Score & Index & Score & Index & Score & \\
\hline Benchmark & 0.3111 & 3.00 & 0.4095 & 2.3 & 0.2811 & 3.33 & -- \\
\hline Strategy 1 & $\begin{array}{c}0.1351 \\
(\mathbf{5 6 . 5 7 \%}) \\
\end{array}$ & 4.00 & $\begin{array}{c}0.2382 \\
\mathbf{( 4 1 . 8 4 \% )}\end{array}$ & 3.67 & $\begin{array}{c}0.1159 \\
\mathbf{( 5 8 . 7 7 \% )} \\
\end{array}$ & 4.00 & $52.39 \%$ \\
\hline Strategy 2 & $\begin{array}{c}0.2509 \\
(\mathbf{1 9 . 3 4 \% )}\end{array}$ & 3.67 & $\begin{array}{c}0.2920 \\
(\mathbf{2 8 . 6 9 \%})\end{array}$ & 3.33 & $\begin{array}{c}0.2347 \\
\mathbf{( 1 6 . 5 0 \% )}\end{array}$ & 3.67 & $21.51 \%$ \\
\hline Strategy 3 & $\begin{array}{c}0.3096 \\
(\mathbf{0 . 4 9 \%})\end{array}$ & 3.00 & $\begin{array}{c}0.3701 \\
(\mathbf{9 . 6 3 \%})\end{array}$ & 2.67 & $\begin{array}{c}0.1166 \\
\mathbf{( 5 8 . 5 3 \% )}\end{array}$ & 4.00 & $22.88 \%$ \\
\hline
\end{tabular}

Table 7. The results of Green Performance Index (GPI).

\begin{tabular}{|c|c|c|c|c|}
\hline \multirow{2}{*}{$\begin{array}{l}\text { Scenario/ } \\
\text { Strategy }\end{array}$} & \multicolumn{4}{|c|}{ Green Performance index (GPI) } \\
\hline & Set $\mathbf{A}$ & Grade & Set B & Grade \\
\hline Benchmark & 2.7980 & $\mathrm{~V}$ & 2.8867 & $\mathrm{~V}$ \\
\hline Strategy 1 & $\begin{array}{c}3.8680 \\
(\mathbf{3 8 . 2 4 \%})\end{array}$ & II & $\begin{array}{c}3.8900 \\
(\mathbf{3 4 . 7 6 \% )}\end{array}$ & II \\
\hline Strategy 2 & $\begin{array}{c}3.5340 \\
(\mathbf{2 6 . 3 0 \%})\end{array}$ & III & $\begin{array}{c}3.5567 \\
(\mathbf{2 3 . 2 1 \%})\end{array}$ & III \\
\hline Strategy 3 & $\begin{array}{c}3.0680 \\
(\mathbf{9 . 6 5 \%})\end{array}$ & IV & $\begin{array}{c}3.2233 \\
(\mathbf{1 1 . 6 6 \% )}\end{array}$ & IV \\
\hline
\end{tabular}

For GNI, it could be seen that Strategy 1 yields a significant improvement with $58.77 \%$. This strategy is quite comparable with Strategy 3 that improved $58.53 \%$. This shows that the both load factor increment (Strategy 1) and fleet planning (Strategy 3) would affect the reduction of noise level significantly. In particular for Strategy 3, a smaller bus with 40 seats was used to service bus routes R1, R2, R9 and R10 while increasing the load factor of these bus routes up to $50 \%$.

In overall, the results show that Strategy 1 outperforms the other improvement strategies with an average improvement level of $52.39 \%$. By comparison, it could be seen that the effect of Strategy 1 is more than double the effect of Strategies 2 and 3. And, Strategy 3 was found to yield an average improvement level of $22.88 \%$, which is slightly better than Strategy 2 that improved $21.51 \%$. This happened mainly due to its greater impact on GNI (which improved $58.53 \%$ ). Approximately, for every $1 \%$ increment of load factor (Strategy 1), there is a potential increase of $4.56 \%$ for the average improvement level (for GEI, GMI and GNI) while the GPI would improve about 3\%. As for Strategy 2 that focuses on the adjustment of bus frequency, there is an average improvement level of $1.96 \%$ for the green indexes while the GPI would improve about $2.11 \%-2.39 \%$ for every reduction of bus frequency. For the fleet 
planning in terms of the changes of bus capacity (Strategy 3), the results show that there is an average improvement level of $2.54 \%$ for all indexes while GPI would improve about $1.07 \%-1.30 \%$ for every reduction of bus seat.

In addition, the results in Table 7 show that Strategy 1 was capable of improving the overall green performance, in terms of the GPI, from grade V (benchmark scenario) up to grade II. This is followed by Strategy 2 that results in grade III and Strategy 3 with grade IV. Besides, the results in Table 7 also highlight that different set of weightage would produce varying green performance. Set A was found to yield a better improvement level for Strategy 1 and 2 (but not Strategy 3). However, the GPI was found to be better for all strategies by using the weightage of Set B. This signifies that a larger improvement level does not necessarily yield a better green performance (although the resultant grading might be the same). This highlights that the weightage selection should be handled with care by the EB operators so that a greener EB operating system could be assured.

Concisely, the resultant findings highlight that the effectiveness of different improvement strategy on the respective environment factor, i.e. Strategy 1, with grade II, is the most effective strategy to improve all the three green indexes (GEI, GMI and GNI) as well as the overall the GPI in terms of grading. It is also noticeable that Strategy 3 could impose great impact in improving GNI while Strategy 2 is more effective to improve GMI (in comparison to GEI and GNI). In overall, the positive effect of all proposed strategies (increasing load factor, adjusting bus frequency and fleet planning) in improving the green performance is in accordance with the facts revealed by Carrese et al. [49] and Titos et al. [50] as well as the application for air transportation sector [43]. Besides, it is important to take note that the overall improvement level (in terms of the average value) is largely dependent on the resultant green index and the finalized grade of green performance is greatly influenced by the respective green score as well as its weightage.

\section{Conclusions}

By capturing numerous environmental factors (i.e. energy consumption, emission and noise), this paper deals with the assessment framework in quantifying the environmental performance of electric bus operational system. To the best of the understanding of the authors, this is the first study that developed such a modeling framework to perform the green analysis of electric bus. The presented approach should be useful to the bus operators to operate electric bus viably and environmentally. Besides, this paper also contributes to the application concept of Gini coefficient in practical use. In particular, the resultant findings highlight that the green performance of electric bus is greatly affected by various elements, including bus route, load factor, bus frequency and also bus capacity. Besides, the results confirmed that the incorporation of effective improvement strategies in operating electric bus would further enhance the green performance of the entire operating network. Yet, the selection of weightage should be handled with care. Future work may focus on how to quantify the relevant weightage by considering the needs of the bus operators. Additionally, this study can be applied in solving the relevant electric bus optimization problem.

The authors would like to express their sincere appreciation to Universiti Tunku Abdul Rahman (Malaysia) for all kind of support in working out this paper.

\section{References}

1. H.C. Ong, T. Mahlia, H.H. Masjuki, Renewable and Sust. Energy Reviews 15, 3516 3522 (2011) 
2. S. Shahid, A. Minhans, O.C. Puan, Jurnal Teknologi (Sciences \& Eng.) 70, $1-8$ (2014)

3. A.A. Juan, C.A. Mendex, J. Faulin, J.d. Armas, S.C. Grasman, Energies 9, 1 - 21 (2016)

4. Q. Song, Z. Wang, Y. Wu, J. Li, D. Yu, H. Duan, W. Yuan, J. of Cleaner Prod. 172, 2133 - 2142 (2018)

5. R. Doucette, M. McCulloch, Energy Pol. 39, 803 - 811 (2011)

6. B.D. Jouman, Iskandar Malaysia: Towards green growth (Iskandar Regional Development Authority, Malaysia, 2013)

7. M. Foltyński, Procedia - Soc. and Behav. Sciences 151, 48 - 59 (2014)

8. Z. Li, M. Ouyang, Energy 36, 5765 - 5778 (2011)

9. J. Gill, P. Bhavsar, M. Chowdhury, J. Johnson, J. Taiber, R. Fries, Procedia Compt. Sci, 32, 545 - 552 (2014)

10. K.C. Bayindir, M.A. Gozukucuk, A. Teke, Energy Conv. and Mgmt. 52, 1305 - 1313 (2011)

11. J. Miles, S. Potter, Res. in Trans. Econ. 48, 357 - 363 (2014)

12. J.P. Ribau, C.M. Silva, J.M.C. Sousa, Appl. Energy 129, 320 - 335 (2014)

13. J.Y. Yong, V.K. Ramachandaramurthy, K.M. Tan, N. Mithulananthan, Renewable and Sustainable Energy Reviews 49, 365 - 385 (2015)

14. A. Elgowainy, A. Rousseau, M. Wang, M. Ruth, D. Andress, J. Ward, F. Joseck, T. Nguyen, S. Das, Energy for Sust. Dev. 17, 626 - 641 (2013)

15. J. Fontaínhas, J. Cunha, P. Ferreira, Energy 115, 1459 - 1477 (2016)

16. W. Jing, Y. Yan, I. Kim, M. Sarvi, Advances in Mechanical Eng. 8, 1 - 8 (2016)

17. G. Brandstatter, C. Gambella, M. Leitner, E. Malaguti, F. Masini, J. Puchinger, M. Ruthmair, D. Vigo, Dynamic perspectives on managerial decision making (Springer, $441-471,2016)$

18. J. Van Mierlo, G. Maggetto, P. Lataire, Energy Conv. and Mgmt. 47, 2748 - 2760 (2006)

19. Z. Zivanovic, Z. Nikolic, New generation of electric vehicles (2012)

20. M. Catenacci, E. Verdolini, V. Bosetti, G. Fiorese, Energy Pol. 61, 403 - 413 (2013)

21. S. Boren, L. Nurhadi, H. Ny, Int. J. of Env., Chem., Eco., Geo., and Geophys. Eng. 10, $255-264$ (2016)

22. M. Gallet, T. Massier, T. Hamacher, Appl. Energy 230, 344 - 356 (2018)

23. D. Perrotta, J.L. Macedo, R.J.F. Rosetti, J.F.d. Sousa, Z. Kokkinogenis, B. Ribeiro, J.L. Afonso, Procedia - Soc. and Behav. Sciences 111, 1004-1014 (2014)

24. A. Bunzel, B. Baker, Energy consumption of electric city buses: determination as a part of a technological and economic evaluation of bus lines with regards to their electrifiability, in Proceedings of the IEEE 5th International Conference on Electrical Systems for Aircraft, Railway, Ship Propulsion and Road Vehicles \& International Transportation Electrification Conference, ESARS-ITEC, 7-9 November 2018, Nottingham, United Kingdom (2018)

25. X. He, S. Zhang, W. Ke, Y. Zheng, B. Zhou, X. Liang, Y. Wu, J. of Cleaner Prod. 171, $714-722$ (2018)

26. D. Dreier, S. Silveira, D. Khatiwada, K.V.O. Fobseca, R. Nieweglowski, R. Schepanski, Trans. Res. Part D 58, 122 - 138 (2018) 
27. Volvo, http://www.bullernatverket.se/wp-content/uploads/2014/05/Electric-buses-andnoise_Volvo-Bus.pdf (2016)

28. T. Münzel, T. Gori, W. Babisch, M. Basner, Eur. Heart J. 35, 829 - 836 (2014)

29. J.C. Ross, M.A. Staiano, A comparison of green and conventional diesel bus noise levels (2007)

30. S. Boren, Int. J. of Sustainable Trans., Doi: 10.1080/15568318.2019.1666324 (2019)

31. FCH-JU. Urban Buses: Alternative Powertrains for Europe (The Fuel Cells and Hydrogen Joint Undertaking, 2012)

32. A. Lajunen, Trans. Res. Part C 38, 1 - 15 (2014)

33. C. Lin, K.L. Choy, G.T.S. Ho, S.H. Chung, H.Y. Lam, Energy Sys. with Appl. 41, $1118-1138$ (2014)

34. B. Beltran, S. Carrese, E. Cipriani, M. Petrelli, Trans. Res. Part C 17, 475 - 483 (2009)

35. M. Pternea, K. Kepaptsoglou, M.G. Karlaftis, Trans. Res. Part A 77, 276 - 291 (2015)

36. B-R. Ke, C-Y. Chung, Y-C. Chen, Appl. Energy 177, 649 - 660 (2016)

37. C. Zhu, X. Chen, Procedia-Soc. and Behav. Sciences 96, 2725 - 2736 (2013)

38. M., Mohamed, H., Farag, N., El-Taweel, M., Ferguson, Elec. Pwr. Sys. Res. 142, 163 175 (2017)

39. G. Fusco, A. Alessandrini, C. Colombaroni, M.P. Valentini, Procedia-Soc. and Behav. Sciences 87, 234 - 249 (2013)

40. M. Rogger, S. Wollny, D.U. Sauer, Energies 8, 4587 - 4606 (2015)

41. N. Qin, A. Gusrialdi, R.P. Brokket, A. T-Raissi, Trans. Res. Part A 94, 386- 396 (2016)

42. M. Xylia, S. Leduc, P. Patrizio, F. Kraxner, S. Silveira, Trans. Res. Part C 78, 183 200 (2017)

43. L.E. Teoh, Optimal airline fleet planning and management strategies under stochastic demand (Thesis of Doctor of Philosophy In Engineering, Universiti Tunku Abdul Rahman, 2015)

44. Putrajaya Corporation, Putrajaya low carbon green city initiatives report (Perbadanan Putrajaya, Malaysia, 2012)

45. A. Muthuvel, M.K. Murthi, N.P. Sachin, V.M. Koshy, S. Sakthi, E. Selvakumar, Int. J. of Scientific \& Eng. Res. 4, 2453 - 2457 (2013)

46. The Engineering ToolBox, https://www.engineeringtoolbox.com/sound-pressured_711.html (2004)

47. L.E. Teoh, H.L. Khoo, S.Y. Goh, L.M. Chong, Int. J. of Trans. Sci. and Tech. 7, $10-$ 25 (2018)

48. Auto-Che, http://auto-che.com/v/xmq/xmq6850agbevl2-291-king-long.html (2020)

49. S. Carrese, A. Gemma, S.L. Spada, Procedia - Soc. and Behav. Sciences 87, 211 - 221 (2012)

50. G. Titos, H. Lyamani, L. Drinovec, F.J. Olmo, G.Močnik, L. Alados-Arboledas, Atm. Env. 114, 19 - 31 (2015) 